Document downloaded from:

http://hdl.handle.net/10251/66371

This paper must be cited as:

Li, Z.; Martínez Triguero, LJ.; Yu, J.; Corma Canós, A. (2015). Conversion of methanol to olefins: Stabilization of nanosized SAPO-34 by hydrothermal treatment. Journal of Catalysis. 329:379-388. doi:10.1016/j.jcat.2015.05.025.

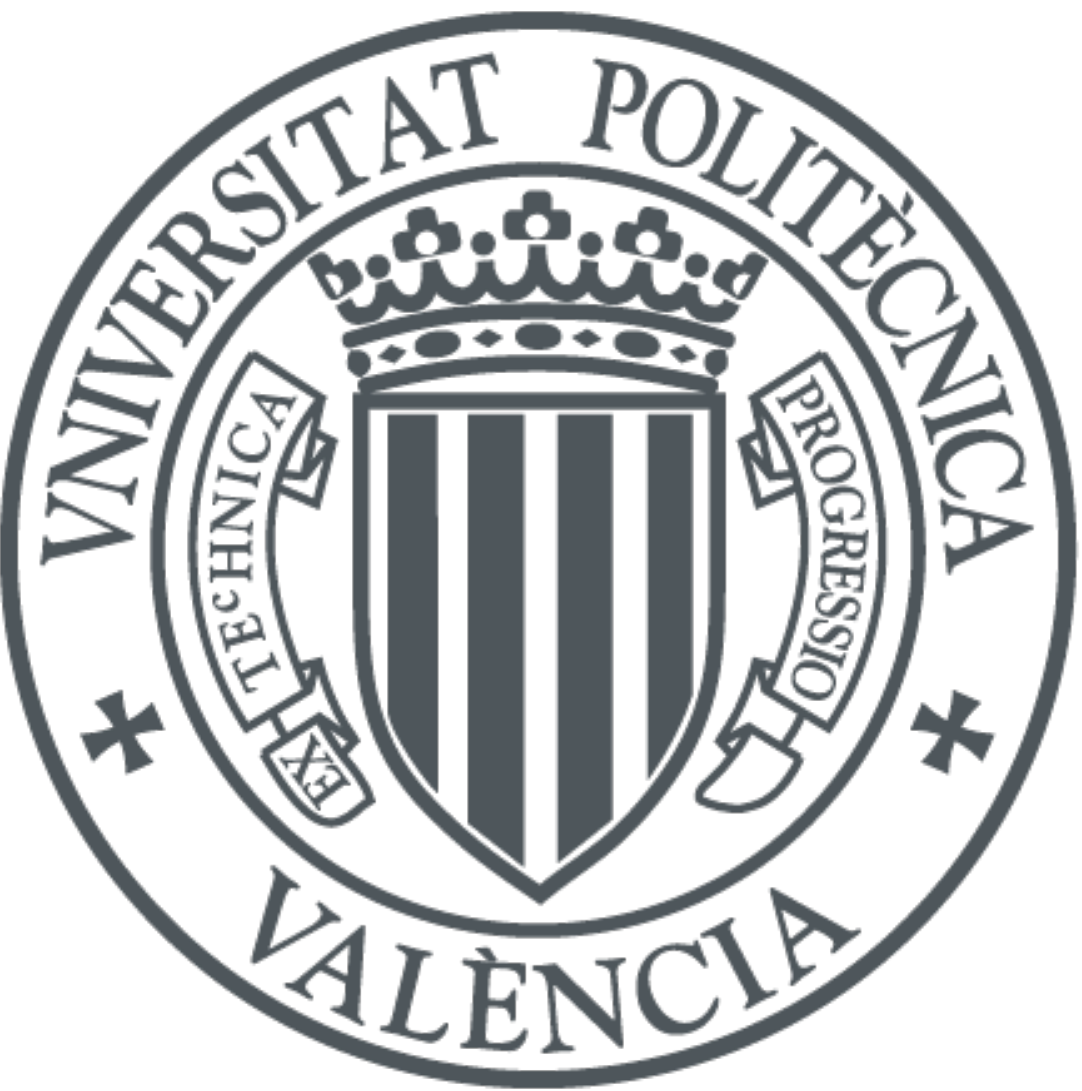

The final publication is available at

http://dx.doi.org/10.1016/j.jcat.2015.05.025

Copyright Elsevier

Additional Information 


\section{Conversion of methanol to olefins: Stabilization of nanosized SAPO-34 by hydrothermal treatment}

Zhibin $\mathrm{Li}^{1}$, Joaquín Martínez-Triguero ${ }^{1}$, Jihong $\mathrm{Yu}^{2}$, Avelino Corma ${ }^{1 *}$

${ }^{1}$ Instituto de Tecnología Química (UPV-CSIC), Universidad Politécnica de Valencia, Consejo Superior de Investigaciones Científicas, Av. de los Naranjos s/n, 46022 Valencia, Spain

${ }^{2}$ State Key Laboratory of Inorganic Synthesis and Preparative Chemistry, College of Chemistry, Jilin University, Changchun, 130012, China

* Corresponding author:

Prof. Avelino Corma

E-mail address: acorma@itq.upv.es

Instituto de Tecnología Química, UPV-CSIC, Campus de la Universitat Politècnica de València

Avda. Los Naranjos s/n; 46022 Valencia (Spain)

(+34) 963877800 


\begin{abstract}
Nano-SAPO-34 zeolite catalyst (20 nm crystal size) has been stabilized by hydrothermal treatment. After steamed at high temperatures $\left(\mathrm{T} \geq 550^{\circ} \mathrm{C}\right)$, its textural properties and high lifetime during the reaction of methanol to olefins (MTO) are preserved, despite the decrease in acidity, even after months of contact with moisture. The stabilization effect is attributed to the migration of silicon to larger silicon islands in which the contribution of silicon on the edge is lower after steaming. Stabilization is not successful by a thermal treatment in air in the absence of water. Steaming at temperature $>400^{\circ} \mathrm{C}$ is required for achieving hydrothermal stabilization. A stability test for SAPO-34 in MTO reaction is proposed.
\end{abstract}

\title{
Keywords
}

Methanol conversion, SAPO-34, deactivation, hydrothermal stabilization, nanocrystal.

\section{Introduction}

Nowadays, the high industrial demand for ethylene and propylene has renewed the interest on the reaction of methanol to olefins (MTO). In fact, more than 20 units are expected to operate in China in the next 2-3 years with an overall olefin capacity of more than 11 million Ton/year [1]. The feed methanol is obtained from reaction of synthesis gas on appropriate catalysts, being the synthesis gas obtained by gasification of coal or biomass and by steam-reforming of natural gas. The increasing amount of gas reserves due to the upcoming of shale gas have led to cheaper methane [2] and are expected to affect the market of methanol, renewing the interest for the MTO process [3]. If propylene is desired the catalyst used is based on high silica ZSM-5 (MTP process), which has a lifetime of $650 \mathrm{~h}$ in between the regeneration steps [4]. Another possibility is to use a catalyst based on silicoaluminophosphate SAPO-34 that can yield different $\mathrm{C} 2=/ \mathrm{C} 3=$ ratios depending on reaction conditions [5-7]. However, the latter catalyst has a much shorter lifetime than ZSM-5 due to the extension of coking reactions inside the cages of the CHA structure, and a continuous catalyst regeneration 
process is required. Lifetime of SAPO-34 can be extended by using mesoporous SAPO34 [8-12], by decreasing the size of the crystal [13-18] or by including metal oxides in the catalyst composition [19]. Smaller crystallites of SAPO-34 were achieved recently by heating the synthesis gel in a microwave apparatus [20, 21]. In this way, crystallites of 20nm sizes were obtained, and the resultant SAPO-34 presented much longer lifetimes than standard SAPO-34 samples. However, due to the small size of crystallites and the high external surface area, the material was very sensitive to hydrolysis by moisture at room conditions and suffered complete hydrolysis after months of storage. This behavior was already reported in the literature for more conventional SAPO-34 samples [22-25]. Briend et al. [22] related the lack of long-term stability to the presence of silicon islands, favored by the use of morpholine as template. Other authors [23, 26] showed that the structural deterioration can be prevented if after removing the template the acid sites are covered with ammonia.

In the present work we started from the hypothesis that it could be possible to increase the stability of SAPO-34 samples by performing a controlled hydrolysis of a part of the silicon, in an analogous way as it occurs with high aluminum zeolites that can be stabilized by controlled partial dealumination [27]. Therefore, we will present here the effect of the hydrothermal treatment at different temperatures on the long-term stability of nano and standard SAPO-34 materials. We will show how by an appropriate steaming temperature, nano-SAPO-34 becomes stabilized towards moisture. In addition, we will show that hydrothermal stability tests for SAPO-34, which are normally performed at very high temperatures $\left(800^{\circ} \mathrm{C}\right)[1,28,29]$, should also include stability tests at reaction temperatures close to the reaction temperature used for MTO, to better ascertain the viability of this type of catalyst for the mentioned catalytic process.

\section{Experimental.}

\subsection{Synthesis of materials}

Nano-SAPO-34 was synthesized by microwave heating following the methodology of Lin et al. [13] and reported previously [21] by using TEAOH as the structure directing agent (SDA). The composition of the synthesis gel was $1 \mathrm{Al}(\mathrm{OPri})_{3}: 2$ $\mathrm{H}_{3} \mathrm{PO}_{4}: 2 \mathrm{TEAOH}: 0.3 \mathrm{SiO}_{2}: 30 \mathrm{H}_{2} \mathrm{O}: \mathrm{Al}(\mathrm{OPri})_{3}$. The crystallization was conducted in a microwave oven (Milestone ETHOS-D) with pre-programmed heating profiles at $180^{\circ} \mathrm{C}$ for 1 hour. Then, the solid product was recovered by filtration washed with water and ethanol for 3 times and dried overnight at $50^{\circ} \mathrm{C}$. The as-synthesized material was 
calcined at $550^{\circ} \mathrm{C}$ in air for $6 \mathrm{~h}$ to remove the SDA. A conventional sample of SAPO-34 was synthesized following hydrothermal method, with a mixture of morpholine and TEAOH 1:1 mol/mol as SDA being the composition of the gel $1 \mathrm{Al}_{2} \mathrm{O}_{3}: 1.06 \mathrm{P}_{2} \mathrm{O}_{5}$ : $1.08 \mathrm{SiO}_{2}: 2.09 \mathrm{SDA}: 66 \mathrm{H}_{2} \mathrm{O}$. The solution was introduced into Teflon-line autoclave and heated at $200^{\circ} \mathrm{C}$ for $24 \mathrm{~h}$. Then, the sample was treated following the same procedure to remove the SDA. This sample will be called standard-SAPO-34.

\subsection{Characterization.}

BET surface area, micropore volume and pore volume distribution were determined by $\mathrm{N}_{2}$ adsorption and desorption in an ASAP2000. Crystallinity was measured by X-ray powder diffraction (XRD) with a Panalytical CUBIX diffract meter with monochromatic $\mathrm{CuK} \alpha 1,2$ radiation $(\lambda=1.5406,1.5444 \AA$; $\mathrm{K} \alpha 2$ / K $\alpha 1$ intensity ratio=0.5). Chemical composition was analyzed by inductively coupled plasma atomic absorption spectroscopy (ICP-OES) using a Varian 715-ES apparatus. Acidity was measured by $\mathrm{NH}_{3}$-TPD experiments carried out in a Micromeritics 2900 following the procedure reported earlier[17]. The MAS NMR spectra were recorded with a Bruker AV400 spectrometer. ${ }^{29} \mathrm{Si}$ MAS NMR spectra were at $79.459 \mathrm{MHz}$ with a $60^{\circ}$ pulse length of $4 \mu \mathrm{s}$ and 60 s repetition time, spinning the sample at $5 \mathrm{kHz}$. Deconvolution of ${ }^{29} \mathrm{Si}$ NMR bands corresponding to different Si environments was performed with Origin Pro 9.0 software with Gaussian shapes of constant width. ${ }^{27} \mathrm{Al}$ MAS NMR spectra were recorded at $104.218 \mathrm{MHz}$ with a spinning rate of $10 \mathrm{kHz}$ at a $90^{\circ}$ pulse length of $0.5 \mu$ s with $1 \mathrm{~s}$ repetition time. ${ }^{31} \mathrm{P}$ MAS NMR spectra were recorded at 161.9 $\mathrm{MHz}$ with a spinning rate of $10 \mathrm{kHz}$ and at a $90^{\circ}$ pulse length of $5 \mu$ s with $20 \mathrm{~s}$ repetition time. ${ }^{29} \mathrm{Si},{ }^{27} \mathrm{Al}$ and ${ }^{31} \mathrm{P}$ chemical shifts are reported relative to tetramethylsilane, $\mathrm{Al}\left(\mathrm{H}_{2} \mathrm{O}\right)_{6}$, and $\mathrm{H}_{3} \mathrm{PO}_{4}$ respectively.

\subsection{Catalytic experiments}

$50 \mathrm{mg}$ of sample (0.2-0.4 mm) were mixed with $2 \mathrm{~g}$ quartz (Fluka) and placed in a quartz reactor. Methanol was fed by saturating $\mathrm{N}_{2}(19 \mathrm{~mL} / \mathrm{min})$ at $25^{\circ} \mathrm{C}$, being the space velocity WHSV $=7 \mathrm{~h}^{-1}$. The catalyst was first activated with a nitrogen flow of 80 $\mathrm{ml} / \mathrm{min}$ for $1 \mathrm{~h}$ at $540^{\circ} \mathrm{C}$, and then the temperature was decreased to reaction conditions $\left(400^{\circ} \mathrm{C}\right)$. Analysis of products was done each $5 \mathrm{~min}$ with an online gas chromatograph (BRUKER 450GC, with a 50m PONA and $\mathrm{Al}_{2} \mathrm{O}_{3}$-Plot capillary columns at $37^{\circ} \mathrm{C}$ of oven temperature, and two FID detectors). After reaction, the catalyst was regenerated 
at $540^{\circ} \mathrm{C}$ in $80 \mathrm{ml}$ of air for $3 \mathrm{~h}$ and the reaction was repeated again. Conversion and selectivities were calculated in carbon basis being methanol and dimethylether considered as feed.

\section{Results and discussion}

\subsection{Crystallinity and acidity of SAPO-34 samples.}

The XRD patterns of the calcined parent nano-SAPO-34 and steamed at different temperatures are shown in Fig.1. The broad shape and low intensity of the XRD of the parent material is characteristic of the small size of the crystals [21], which is around 20 $\mathrm{nm}$ (see Fig. 2). After steaming at temperatures of $550^{\circ} \mathrm{C}$ and $600^{\circ} \mathrm{C}$, the diffraction patterns are still similar to that of nano-SAPO-34 suggesting that the structure of these samples is maintained. At $700^{\circ} \mathrm{C}$ a slight decrease in the intensity of the peaks is observed. However, the sample steamed at $400^{\circ} \mathrm{C}$ presents amorphous XRD pattern. In agreement with the XRD results, adsorption of nitrogen (Table 1) shows that the nanoSAPO-34 steamed at $400^{\circ} \mathrm{C}$ loses the microporosity while those steamed at higher temperatures preserve most of the textural properties with an optimum in microporosity for the sample steamed at $600^{\circ} \mathrm{C}$. Even more important is the observation that for samples steamed at $\mathrm{T} \geq 550^{\circ} \mathrm{C}$ and exposed to moisture during days at room temperature, their crystallinity and micropore volume are preserved (Table 1 and Fig. 3), while non steamed template-free nano-SAPO-34 is negatively affected when exposed to moisture at room temperature. On the other hand, standard-SAPO-34 with larger cubic crystallites of around $500 \mathrm{~nm}$ is much less affected by steaming, with a smaller decrease in the BET surface after steaming at low (400) and high $\left(700^{\circ} \mathrm{C}\right)$ temperatures.

When the acidity of the samples was measured by TPD of ammonia (Table 1 and Figure 4) the results indicate that, in general, steaming reduces the acidity of the samples when compared to the parent sample. This decrease is stronger in the case of the steaming at $700^{\circ} \mathrm{C}$, while the samples steamed at 550 and $600^{\circ} \mathrm{C}$ present very similar acidity. When comparing the shape of the TPD desorption curves, it can be seen that all samples present a main component with a maximum in the range from 314 to $381^{\circ} \mathrm{C}$, and a shoulder ca. $230^{\circ} \mathrm{C}$ (Fig. 3). The peak at higher temperature of desorption corresponds mainly to Brönsted acidity and the differences in the temperature of the maxima are better related to the amount of acid sites than to differences in acidity strength. The shoulder at low temperatures corresponds to physisorption of ammonia 
and not to adsorption on catalytically active sites [30]. From the amounts of adsorbed ammonia given in Table 1, it can be seen that the decrease in acidity is proportionally larger than the decrease in micropore volume when increasing steaming temperatures (see Fig. 4). The results suggest that the hydrolysis of the acid sites when steaming do not necessarily imply a loss of crystallinity, i.e., a partial collapse of the structure but, as it occurs during a controlled steam dealumination process for high $\mathrm{Al}$ content zeolites in which silicon is reinserted in the framework, in the case of SAPO-34 can occur a migration of phosphorus to fill up some of the nests left by silicon. Let's investigate now by solid NMR the physicochemical transformations occurring in SAPO-34 upon steaming.

\subsection{Solid NMR characterization.}

The ${ }^{27} \mathrm{Al}$ MAS NMR spectra of nano-SAPO-34 given in Fig. 5 show an intense peak at $36 \mathrm{ppm}$ and other two signals at -11 and 14 ppm for calcined nano-SAPO-34, that correspond to tetrahedrally coordinated aluminum in local structures of $\mathrm{Al}(\mathrm{PO})_{4}$, and octa and pentacoordinated aluminum, respectively. After exposing the calcined sample to moisture at room temperature at increasing times, the octahedral $\mathrm{Al}$ signal at $14 \mathrm{ppm}$ continuously increases, indicating hydration of the $\mathrm{Al}(\mathrm{PO})_{4}$ species [24, 31]. Meanwhile, the signal of tetrahedral aluminum is shifted to $41 \mathrm{ppm}$, due to the distortion of the structure by interaction with water [32]. The ${ }^{27} \mathrm{Al}$ MAS NMR spectra of nano-SAPO-34 sample steamed at $700^{\circ} \mathrm{C}$ presents band intensities which are independent of the time of exposure and only a slight increase of octahedral aluminum is observed, indicating an increasing hydration effect with time.

The hydration effect is also evidenced through the ${ }^{31} \mathrm{P}$ NMR spectra. NanoSAPO-34 exhibits an asymmetrical signal at $-30 \mathrm{ppm}$ corresponding to tetrahedral $\mathrm{P}(\mathrm{OAl})_{4}$. After 21 days of hydration, another signal at $-16 \mathrm{ppm}$ appears, which can be attributed to $\mathrm{P}(\mathrm{OAl})_{\mathrm{x}}\left(\mathrm{H}_{2} \mathrm{O}\right)_{y}$ formed by $\mathrm{P}$ atoms coordinated with water [24, 26, 33]. After steaming the fresh nano-SAPO-34 sample at $700^{\circ} \mathrm{C}$, the shoulder at $-16 \mathrm{ppm}$ appears, and slightly increases after long contact with moisture. This result correlates well with the increase in the signal of $\mathrm{Al}$ NMR at $-14 \mathrm{ppm}$ assigned to the hydration of the $\mathrm{Al}(\mathrm{PO})_{4}$ species.

The ${ }^{29}$ Si MAS NMR spectra give further information, and clear differences are observed with the hydrated-parent and steamed samples (Figure 5 and Table 2). The different silicon species of nano-SAPO-34 have been described elsewhere [21]. This 
sample shows a large amount of silicon in silicon islands, Si3Al, Si2Al, Si1Al and Si0Al, which corresponds to the $-95,-100,-, 105$ and -110 ppm bands respectively, and isolated silicon which is related to the band at $-89 \mathrm{ppm}$. The fresh nano-SAPO-34 sample was shown to hydrolyze in contact with moisture by transforming silicon at the edge of the silicon islands (-95 ppm) into defective sites at -78-85 ppm. As we will see later this has an effect in activity, selectivity and deactivation of the catalyst during the reaction of methanol to olefins. However, when the fresh calcined sample is steamed, the population of isolated silicon Si4Al decreases which is in agreement with the reduction in acidity shown by TPD of ammonia. At the same time, the signals corresponding to silicon within silicon islands, especially Si0Al at $-110 \mathrm{ppm}$, increases together with a reduction of silicon on the edge ( $\mathrm{Si3Al}$ at -95$)$ with no raise in defects (78 to -85 ppm). In addition, the distribution of silicon species is not importantly affected when the steamed samples are contacted with moisture at room temperature. The above described effects are qualitatively similar for the sample steamed at 600 and $700^{\circ} \mathrm{C}$, being the decrease of isolated silicon Si4Al species higher for the sample steamed at $700^{\circ} \mathrm{C}$.

The results obtained here are in line with those previously reported for SAPO-34 and other SAPO's [31, 34, 35], in the sense that when they were thermally treated at high temperatures in the absence of added steam, part of silicon migrates to silicon islands while phosphorus healed the framework vacancies with no formation of defects. However, we have seen clear differences in the population of the different Si species and an impact on stability when the samples were steamed. The question then is what is the effect of steaming on the framework composition and its implication on stability to moisture, acidity, activity and selectivity for MTO.

Wilson and Barger [7, 36] studied the effect of hydrothermal treatment on the activity and selectivity of SAPO-34 and they observed no degradation of the structure and a longer lifetime. Recently, Aramburo et al. [25] reported no difference with the purely thermally treated samples [31, 34, 35], i.e., a reduction in acidity with migration of silicon species to silicon islands. However, in an earlier contribution Park et al. [37] showed that SAPO-34 thermally treated at $750^{\circ} \mathrm{C}$ loses more crystallinity after reaction with water than the fresh sample indicating that only thermal treatment does not stabilize SAPO-34 samples. If our original hypothesis on the positive effect of water on the mobility of silicon and phosphorus through the framework of SAPO-34, in a similar way as it occurs with aluminum and silicon during ultrastabilization without generation 
of defects in zeolites, was possible in SAPO-34, a controlled steaming of the SAPO should stabilize towards the negative effect of moisture at room conditions on crystallinity. In this case, steam at high temperatures should facilitate the formation of larger silicon islands together with an easier reallocation of phosphorus occupying the vacancies left by silicon. This hypothesis is supported by a smaller amount of silicon species on the edge of the silicon islands found in steamed samples, as deduced from silicon NMR with an increase in the signals of silicon islands upon steaming. Theoretical calculations on the role of steaming on clusters of isomorphous zeolite SSZ13 and SAPO-34 [38] also to support our hypothesis on the effect of steaming on SAPO-34 stability.

In summary, we can say that steaming produces a decrease of isolated Si species and its migration to silicon islands which grow in size, as suggested by the decrease of silicon species at the edge of silicon islands. The effect of steaming on lowering the amount of Si at the border of Si islands can explain the lower extension of hydrolysis in the steamed samples upon exposure to moisture at room temperature. This, in turn, would be responsible for the higher stability of the steamed samples.

\subsection{Catalytic activity.}

3.3.1 Influence of stabilization on catalyst activity and lifetime.

The activity of calcined and steamed nano-SAPO-34 is shown in Fig. 7. The experiments were performed at WHSV $=7 \mathrm{~h}^{-1}$ and $400^{\circ} \mathrm{C}$ of reaction temperature. NanoSAPO-34 samples steamed at 550,600 and $700^{\circ} \mathrm{C}$ present a lifetime close to fresh nanoSAPO-34, though clear differences appear in the slope or the time at which catalyst deactivation starts to be observed. Here we have fitted the experimental data to the kinetic model developed by Janssens [39]. This model is able to separate the contribution of activity (K) from the deactivation rate (a) on ZSM-5 and was also successfully applied to SAPO-34 [21]. By doing that, the effect of steaming temperature is clearly visible. Indeed, the results in Table 3 indicate that activity (K) decreases when increasing the steaming temperature and that decrease correlates well with the decrease of acidity measured by TPD of ammonia. On the other hand, the rate of deactivation, which is also a measure of the catalyst half lifetime, is maintained despite the decrease of overall acidity due to steaming. Therefore, steaming decreases the activity of the catalyst while deactivation rate does not increase. However, the most important observation is that the samples steamed at temperatures $\geq 550^{\circ} \mathrm{C}$ present a similar 
activity and lifetime after days, and even months, of contact with moisture at room temperature. This result would be consistent with the preservation of micropore volume and acidity of steamed samples observed upon exposure to moisture for long periods of time. The long-term stability must be related to the decrease of silicon at the edge of silicon islands due to both, migration of silicon and merging of small to larger islands in which the contribution of edges is less important. In addition, the decrease of Si species at the edge ( $\mathrm{Si} 3 \mathrm{Al})$ is also responsible for the longer lifetime of the remaining acid sites since those sites have been considered strongly acid [40-42] and thus, more prone to deactivation by coking.

When the micropore volume of steamed samples of nano-SAPO-34 was plotted versus the temperature of steaming, it appears that an optimum steaming temperature may exist between 600 and $700^{\circ} \mathrm{C}$. In fact, at lower steaming temperatures samples are hydrolyzed as shown by BET measurements, while at higher temperatures the decrease in acidity produced is larger with the correspondent loss of activity observed (Fig. 4).

Finally, a sample of nano-SAPO-34 which was only thermally treated in air at $750^{\circ} \mathrm{C}$ was also tested when fresh and after being in contact with moisture at increasing times. It can be clearly seen in Figure 8 that despite the high initial lifetime of the fresh thermally treated sample, this strongly decreases when contacted with moisture. This result is in clear contrast what it occurs with the samples steamed at $\mathrm{T} \geq 550^{\circ} \mathrm{C}$ that retain their microporosity, acidity and activity upon exposure to moisture.

\subsubsection{Influence of stabilization on catalyst selectivity}

Selectivity at constant conversion of the steamed samples is shown in Fig. 9. Notice that in the case of MTO it is mandatory to compare the selectivities at the same level of conversion. By doing that, the effect of thermodynamic equilibrium among olefins at high methanol conversion, can be isolated from the true selectivity of the hydrocarbon pool in SAPO-34. In fact, it was shown recently [21] that as the hydrocarbon pool forms through the catalytic bed, its selectivity is modified by further secondary reaction on the fresh portion of the catalyst, approaching thermodynamic equilibrium and masking therefore the selectivity obtained.

When comparing different selectivities of steamed samples at constant conversion it can be seen that $\mathrm{C}_{2}{ }^{*} / \mathrm{C}_{3}=$ ratio decreases after steaming when compared with calcined nano-SAPO-34, being the decrease more marked at $700^{\circ} \mathrm{C}$ of steaming temperature (Fig. 10). More specifically, the results show an effective decrease of the 
selectivity to ethylene, while the distribution among the other olefins is not affected. This effect on the selectivity of ethylene must be related to the decrease in the strength of the acid sites due to the formation of larger silicon islands and the consequent decrease in the density of silicon species located at the edge, when compared with the calcined parent sample, as it is supported by ${ }^{29} \mathrm{Si}$ NMR results (Table 2).

Previously, when the parent nano-SAPO-34 (20 nm) was compared with a standard SAPO-34 of similar total acidity and much larger crystal size (500nm), nanoSAPO-34 presented much higher $\mathrm{C}_{2}=/ \mathrm{C}_{3}=$ ratio [17], indicating that this ratio is not controlled by a faster diffusion of ethylene vs. propylene [5, 43, 44] but it would support the fact that with a higher acid strength, the olefin selectivity is produced through aromatic intermediates by the side-chain methylation mechanism [45]. If this is so, then a SAPO-34 with higher acid strength should yield more ethene since the formation from a hexa or tetramethylbenzene reaction center is less energetically favoured [46]. In our case, after steaming of nano-SAPO-34, the $\mathrm{C}_{2}{ }{ } / \mathrm{C}_{3}{ }{ }$ ratio also decreases when compared with the parent sample, in line with a decrease in the distribution of silicon species at the edge of silicon islands. We can conclude from the experimental data that selectivity is governed by silicon distribution, (which has been modified by steaming) and not by shape selectivity effects, due to preferential diffusion of ethene or deactivation by coke.

\subsubsection{Methodology suggested for performing SAPO-34 stability tests.}

In addition, the results presented in this contribution help to define which are the best conditions to perform a SAPO-34 stability test that simulates a long period of a working catalyst with many cycles of reactions and regeneration, both in the presence of water. This has been done for other petrochemical process using zeolites in the catalyst inventory as it is the case of Fluid Catalytic Cracking. In this case, steaming at temperatures of $750^{\circ} \mathrm{C}$ or higher and high partial pressures of water are used for simulating an equilibrium catalyst. However, this kind of hydrothermal stability test does not seem suitable for SAPO-34 since the mechanism of dealumination for zeolites is different from the desilication on silicoaluminophosphates [38]. In fact, while steaming at high temperature generates wide dealumination in ZSM-5 crystals with severe loss of acidity [47-49], in the case of standard SAPO-34, both, textural and acidity properties are preserved (see Table 1 and ref. [25]). Moreover, if the SAPO-34 sample presents high mesoporosity, as it is the case of the nano-SAPO-34 sample, steaming at $400^{\circ} \mathrm{C}$ strongly affects the stability. Our results indicate that SAPO-34 
samples, especially if they are of hierarchical nature, should be submitted to hydrothermal stability test at low temperature, similar to the reaction temperature of methanol to olefins in order to evaluate their properties as potential MTO catalyst. Then, if required, they can be stabilized by steaming at $600-700^{\circ} \mathrm{C}$.

\section{Conclusions}

Nano-SAPO-34 has been stabilized towards contact with moisture by steaming at $\mathrm{T} \geq 550^{\circ} \mathrm{C}$. The stabilization effect is attributed to the migration of silicon to larger silicon islands in which the overall contribution of Si species on the edge of silicon islands has been reduced. The role of steam at high temperature is to facilitate the migration of silicon while the vacancies are healed by phosphorus. In the absence of steam, thermally treated nano-SAPO-34 is not stabilized and its lifetime decreases after contact with moisture. At low temperature of steaming the structure of nano-SAPO-34 collapses due to the hydrolysis of Si-O-Al bonds. Suitable hydrothermal stability tests for nanosized or mesoporous SAPO-34 samples should include steaming at temperatures close to the temperature of the reaction of methanol and, if required, stabilization by steaming at $\mathrm{T} \geq 550^{\circ} \mathrm{C}$ should be performed.

\section{Acknowledgements}

Financial support by the Spanish MINECO (MAT2012-37160, CSD2009-00050CONSOLIDER/INGENIO 2010), and Generalitat Valenciana by the PROMETEO program is acknowledged. Z. Li acknowledges China Scholarship Council (CSC) for a fellowship. J. Yu thanks the Major International Joint Research Project of China for financial supports (Grant No. 21320102001).

\section{References}

[1] Z. Liu, Y. Wei, P. Tian, L. Xu, Methanol to olefin: from fundamental to commercialization, in: 17th International Zeolite Conference, Moscow, 2013.

[2] Annual Energy Outlook 2012 with Projections to 2035, in, U.S. Energy Information Administration, 2012.

[3] M. Stöcker, Methanol to Olefins (MTO) and Methanol to Gasoline (MTG), in: Zeolites and Catalysis, Wiley-VCH Verlag GmbH \& Co. KGaA, 2010, pp. 687-711.

[4] H. Koempel, W. Liebner, Lurgi's Methanol To Propylene (MTP ${ }^{\circledR}$ ) Report on a successful commercialisation, in: M.S. Fábio Bellot Noronha, S.-A. Eduardo Falabella (Eds.) Stud. Surf. Sci. Catal., 
Elsevier, 2007, pp. 261-267.

[5] P. Barger, Methanol to olefins (MTO) and beyond, in: M. Guisnet, J.P. Gilson (Eds.) Zeolites for Cleaner Technologies (Catalytic Science Series Vol. 3), Imperial College Press, London, 2002, pp. 239-260.

[6] S. Kvisle, H.R. Nilsen, T. Fuglerud, A. Gronvold, B.V. Vora, P.R. Pujado, P.T. Barger, J.M. Andersen, Methanol to olefins: state of the art and perspectives, Erdoel, Erdgas, Kohle, 118 (2002) 361-365.

[7] S. Wilson, P. Barger, The characteristics of SAPO-34 which influence the conversion of methanol to light olefins, Microporous Mesoporous Mater., 29 (1999) 117-126.

[8] S.T. Yang, J.Y. Kim, H.J. Chae, M. Kim, S.Y. Jeong, W.S. Ahn, Microwave synthesis of mesoporous SAPO34 with a hierarchical pore structure, Mater. Res. Bull., 47 (2012) 3888-3892.

[9] Y. Cui, Q. Zhang, J. He, Y. Wang, F. Wei, Pore-structure-mediated hierarchical SAPO-34: Facile synthesis, tunable nanostructure, and catalysis applications for the conversion of dimethyl ether into olefins, Particuology, 11 (2013) 468-474.

[10] H. Yang, Z. Liu, H. Gao, Z. Xie, Synthesis and catalytic performances of hierarchical SAPO-34 monolith, J. Mater. Chem., 20 (2010) 3227-3231.

[11] J. Zhu, Y. Cui, Y. Wang, F. Wei, Direct synthesis of hierarchical zeolite from a natural layered material, Chem. Commun., (2009) 3282-3284.

[12] F. Schmidt, S. Paasch, E. Brunner, S. Kaskel, Carbon templated SAPO-34 with improved adsorption kinetics and catalytic performance in the MTO-reaction, Microporous Mesoporous Mater., 164 (2012) 214-221.

[13] S. Lin, J. Li, R.P. Sharma, J. Yu, R. Xu, Fabrication of SAPO-34 crystals with different morphologies by microwave heating, Top. Catal., 53 (2010) 1304-1310.

[14] Y. Hirota, K. Murata, S. Tanaka, N. Nishiyama, Y. Egashira, K. Ueyama, Dry gel conversion synthesis of SAPO-34 nanocrystals, Mater. Chem. Phys., 123 (2010) 507-509.

[15] T. Álvaro-Muñoz, C. Márquez-Álvarez, E. Sastre, Effect of silicon content on the catalytic behavior of chabazite type silicoaluminophosphate in the transformation of methanol to short chain olefins, Catal. Today, 213 (2013) 219-225.

[16] T. Álvaro-Muñoz, C. Márquez-Álvarez, E. Sastre, Use of different templates on SAPO-34 synthesis: Effect on the acidity and catalytic activity in the MTO reaction, Catal. Today, 179 (2012) 27-34.

[17] W. Pengfei, Y. Dexing, H. Jie, X. Jing'an, L. Guanzhong, Synthesis of SAPO-34 with small and tunable crystallite size by two-step hydrothermal crystallization and its catalytic performance for MTO reaction, Catal. Today, 212 (2013).

[18] M. Yang, P. Tian, C. Wang, Y. Yuan, Y. Yang, S. Xu, Y. He, Z. Liu, A top-down approach to prepare silicoaluminophosphate molecular sieve nanocrystals with improved catalytic activity, Chemical communications (Cambridge, England), (2014).

[19] S.C. Fung, D. Levin, J. Santiesteban, N.P. Coute, Conversion of oxygenates into olefins using a metal oxide-containing zeolitic molecular sieve catalyst. US Pat. 7166757 (2006).

[20] G. Yang, Y. Wei, S. Xu, J. Chen, J. Li, Z. Liu, J. Yu, R. Xu, Nanosize-Enhanced Lifetime of SAPO-34 Catalysts in Methanol-to-Olefin Reactions, The Journal of Physical Chemistry C, 117 (2013) 8214-8222.

[21] Z. Li, J. Martinez-Triguero, P. Concepcion, J. Yu, A. Corma, Methanol to olefins: activity and stability of nanosized SAPO-34 molecular sieves and control of selectivity by silicon distribution, PCCP, 15 (2013) 14670-14680.

[22] M. Briend, R. Vomscheid, M.J. Peltre, P.P. Man, D. Barthomeuf, Influence of the Choice of the Template on the Short- and Long-Term Stability of SAPO-34 Zeolite, J.Phys.Chem., 99 (1995) 8270-8276.

[23] F.D.P. Mees, L.R.M. Martens, M.J.G. Janssen, A.A. Verberckmoes, E.F. Vansant, Improvement of the hydrothermal stability of SAPO-34, Chem. Commun., 9 (2003) 44-45.

[24] A. Buchholz, W. Wang, A. Arnold, M. Hunger, Successive steps of hydration and dehydration of silicoaluminophosphates H-SAPO-34 and H-SAPO-37 investigated by in situ CF MAS NMR spectroscopy, Microporous Mesoporous Mater., 57 (2003) 157-168.

[25] L.R. Aramburo, J. Ruiz-Martínez, L. Sommer, B. Arstad, R. Buitrago-Sierra, A. Sepúlveda-Escribano, H.W. Zandbergen, U. Olsbye, F.M.F. de Groot, B.M. Weckhuysen, X-Ray Imaging of SAPO-34 Molecular Sieves at the Nanoscale: Influence of Steaming on the Methanol-to-Hydrocarbons Reaction, ChemCatChem, 5 (2013) 1386-1394.

[26] A. Buchholz, W. Wang, M. Xu, A. Arnold, M. Hunger, Sequential Steps of Ammoniation of the Microporous Silicoaluminophosphates H-SAPO-34 and H-SAPO-37 Investigated by In Situ CF MAS NMR Spectroscopy, J. Phys. Chem. B, 108 (2004) 3107-3113.

[27] J. Klinowski, J.M. Thomas, C.A. Fyfe, G.C. Gobbi, Monitoring of structural changes accompanying ultrastabilization of faujasitic zeolite catalysts, Nature, 296 (1982) 533-536. 
[28] J. Zhu, Y. Cui, Y. Wang, F. Wei, Direct synthesis of hierarchical zeolite from a natural layered material, Chemical communications (Cambridge, England), (2009) 3282-3284.

[29] G. Liu, P. Tian, Y. Zhang, J. Li, L. Xu, S. Meng, Z. Liu, Synthesis of SAPO-34 templated by diethylamine: Crystallization process and Si distribution in the crystals, Microporous Mesoporous Mater., 114 (2008) 416-423.

[30] Q. Zhu, J.N. Kondo, T. Tatsumi, S. Inagaki, R. Ohnuma, Y. Kubota, Y. Shimodaira, H. Kobayashi, K. Domen, A Comparative Study of Methanol to Olefin over CHA and MTF Zeolites, Journal of Physical Chemistry C, 111 (2007).

[31] A. Buchholz, W. Wang, M. Xu, A. Arnold, M. Hunger, Thermal stability and dehydroxylation of brønsted acid sites in silicoaluminophosphates H-SAPO-11, H-SAPO-18, H-SAPO-31, and H-SAPO-34 investigated by multi-nuclear solid-state NMR spectroscopy, Microporous Mesoporous Mater., 56 (2002) 267-278.

[32] C.S. Blackwell, R.L. Patton, Solid-state NMR of silicoaluminophosphate molecular sieves and aluminophosphate materials, The Journal of Physical Chemistry, 92 (1988) 3965-3970.

[33] Y. Watanabe, A. Koiwai, H. Takeuchi, S.A. Hyodo, S. Noda, Multinuclear NMR Studies on the Thermal Stability of SAPO-34, J. Catal., 143 (1993) 430-436.

[34] M.J. Peltre, P.P. Man, M. Briend, M. Derewinski, D. Barthomeuf, Changes upon heating of the distribution of Al, P and Si atoms in the SAPO-37 molecular sieve, Catal. Lett., 16 (1992).

[35] D. Miroslav, P. Marie Jeanne, B. Marguerite, B. Denise, P.M. Pascal, Solid-state transformation of SAPO-37 molecular sieve above 1100 K, J. Chem. Soc., Faraday Trans., 89 (1993).

[36] P.T. Barger, D.A. Lesch, Hydrothermal stability of SAPO-34 in the methanol-to-olefins process, Arabian Journal for Science and Engineering, 21 (1996) 263-272.

[37] Y.-K. Park, S.-W. Baek, S.-K. Ihm, Effect of reaction conditions and catalytic properties on methanol conversion over SAPO-34, J. Ind. Eng. Chem. (Seoul, Repub. Korea), 7 (2001) 167-172.

[38] T. Fjermestad, S. Svelle, O. Swang, Mechanistic Comparison of the Dealumination in SSZ-13 and the Desilication in SAPO-34, The Journal of Physical Chemistry C, 117 (2013).

[39] T.V.W. Janssens, A new approach to the modeling of deactivation in the conversion of methanol on zeolite catalysts, J. Catal., 264 (2009) 130-137.

[40] G.A.V. Martins, G. Berlier, S. Coluccia, H.O. Pastore, G.B. Superti, G. Gatti, L. Marchese, Revisiting the nature of the acidity in chabazite-related silicoaluminophosphates: Combined FTIR and29Si MAS NMR study, Journal of Physical Chemistry C, 111 (2007) 330-339.

[41] G. Sastre, D.W. Lewis, C. Richard, A. Catlow, Modeling of silicon substitution in SAPO-5 and SAPO-34 molecular sieves, J. Phys. Chem. B, 101 (1997) 5249-5262.

[42] D. Barthomeuf, Topological model for the compared acidity of SAPOs and SiAl zeolites, Zeolites, 14 (1994) 394-401.

[43] I.M. Dahl, H. Mostad, D. Akporiaye, R. Wendelbo, Structural and chemical influences on the MTO reaction: a comparison of chabazite and SAPO-34 as MTO catalysts, Microporous Mesoporous Mater., 29 (1999) 185-190.

[44] B.P.C. Hereijgers, F. Bleken, M.H. Nilsen, S. Svelle, K.P. Lillerud, M. Bjørgen, B.M. Weckhuysen, U. Olsbye, Product shape selectivity dominates the Methanol-to-Olefins (MTO) reaction over H-SAPO-34 catalysts, J. Catal., 264 (2009) 77-87.

[45] K. Hemelsoet, J. Van der Mynsbrugge, K. De Wispelaere, M. Waroquier, V. Van Speybroeck, Unraveling the Reaction Mechanisms Governing Methanol-to-Olefins Catalysis by Theory and Experiment, ChemPhysChem, (2013) n/a-n/a.

[46] B. Arstad, J.B. Nicholas, J.F. Haw, Theoretical Study of the Methylbenzene Side-Chain Hydrocarbon Pool Mechanism in Methanol to Olefin Catalysis, J. Am. Chem. Soc., 126 (2004) 2991-3001.

[47] T. Blasco, A. Corma, J. Martinez-Triguero, Hydrothermal stabilization of ZSM-5 catalytic-cracking additives by phosphorus addition, J. Catal., 237 (2006).

[48] G. Caeiro, P. Magnoux, J.M. Lopes, F.R. Ribeiro, S.M.C. Menezes, A.F. Costa, H.S. Cerqueira, Stabilization effect of phosphorus on steamed H-MFI zeolites, Applied Catalysis A: General, 314 (2006).

[49] M.T.A. Sami, M. Brahim, A.P. Evgeny, C.M.M.M. Pieter, J.M.H. Emiel, Influence of steaming on the acidity and the methanol conversion reaction of HZSM-5 zeolite, J. Catal., 307 (2013). 
Table 1. Textural properties of nano-SAPO-34 and standard-SAPO-34 samples fresh and steamed at different temperatures after days of exposure to moisture.

\begin{tabular}{cccccccc}
\hline Sample & $\begin{array}{c}\text { Steaming } \\
\text { temperature } \\
\left({ }^{\circ} \mathrm{C}\right)\end{array}$ & $\begin{array}{c}\text { Days with } \\
\text { moisture at } \\
\text { r.t. }\end{array}$ & $\begin{array}{c}\text { BET } \\
\left(\mathrm{m}^{2} \mathrm{~g}^{-1}\right)\end{array}$ & $\begin{array}{c}\mathrm{t} \text {-plot } \\
\mathrm{S}_{\text {ext }} \\
\left(\mathrm{m}^{2} / \mathrm{g}\right)\end{array}$ & $\begin{array}{c}\mathrm{V}_{\text {micro }} \\
\left(\mathrm{cm}^{3} / \mathrm{g}\right)\end{array}$ & $\begin{array}{c}\mathrm{V}_{\text {meso }} \\
\left(\mathrm{cm}^{3} / \mathrm{g}\right)\end{array}$ & $\begin{array}{c}\text { Acidity } \\
(\mathrm{mmol} \\
\left.\mathrm{NH}_{3} \mathrm{~g}^{-1}\right)\end{array}$ \\
\hline $\begin{array}{c}\text { Nano- } \\
\text { SAPO-34 }\end{array}$ & fresh & 1 & 646 & 231 & 0.20 & 0.21 & 1.03 \\
& fresh & 14 & 616 & 224 & 0.19 & 0.20 & 0.86 \\
& fresh & 42 & 561 & 223 & 0.18 & 0.20 & - \\
& fresh & 107 & 536 & 223 & 0.15 & 0.20 & - \\
& 400 & 1 & 120 & 57 & 0.03 & 0.15 & - \\
& 550 & 1 & 534 & 177 & 0.17 & 0.21 & 0.74 \\
& 550 & 7 & 534 & 176 & 0.18 & 0.21 & - \\
& 550 & 14 & 538 & 179 & 0.18 & 0.21 & - \\
& 600 & 1 & 575 & 172 & 0.20 & 0.20 & 0.77 \\
& 600 & 12 & 574 & 173 & 0.20 & 0.20 & - \\
& 600 & 23 & 581 & 180 & 0.20 & 0.21 & - \\
& 700 & 1 & 490 & 143 & 0.17 & 0.18 & 0.43 \\
& 700 & 50 & 488 & 160 & 0.16 & 0.19 & - \\
& 700 & 65 & 491 & 144 & 0.17 & 0.19 & - \\
\hline Standard- & fresh & 5 & 460 & 63 & 0.19 & 0.11 & 1.01 \\
SAPO-34 & & & & & & & \\
& fresh & 29 & 463 & 62 & 0.19 & 0.11 & 0.97 \\
& fresh & 44 & 463 & 64 & 0.19 & 0.11 & 0.95 \\
& 400 & 1 & 432 & 41 & 0.19 & 0.10 & 0.83 \\
& 700 & 1 & 443 & 40 & 0.20 & 0.10 & 0.73 \\
\hline
\end{tabular}


Table 2 Distribution of silicon species by deconvolution of different ${ }^{29} \mathrm{Si}$ MAS NMR signal of samples of nano-SAPO-34 fresh and steamed at 600 or $700^{\circ} \mathrm{C}$ followed by exposure to moisture (days) at room temperature.

\begin{tabular}{l|crrrrrrrr}
\hline Silicon species & ppm & Fresh & $\begin{array}{r}\text { Fresh } \\
(23 d)\end{array}$ & $\begin{array}{c}\text { St-700 } \\
(8 \mathrm{~d})\end{array}$ & $\begin{array}{r}\text { St-700 } \\
(75 \mathrm{~d})\end{array}$ & $\begin{array}{r}\text { St-700 } \\
(90 \mathrm{~d})\end{array}$ & $\begin{array}{c}\text { St-600 } \\
(1 \mathrm{~d})\end{array}$ & $\begin{array}{c}\text { St-600 } \\
(7 \mathrm{~d})\end{array}$ & $\begin{array}{r}\text { St-600 } \\
(21 \mathrm{~d})\end{array}$ \\
\hline Defects & $-78-85$ & 5.1 & 14.3 & 13.9 & 11.5 & 7.9 & 7.4 & 3.5 & 1.5 \\
Si4Al & -89 & 16.3 & 18.7 & 12.2 & 12.9 & 12.8 & 16.1 & 9.4 & 8.5 \\
Si3Al1Si & -95 & 25.6 & 17.2 & 14.6 & 15.2 & 14.9 & 16.9 & 16.2 & 16.7 \\
Si2Al2Si & -100 & 18.9 & 18.8 & 19.8 & 19.7 & 17.0 & 17.7 & 16.6 & 16.8 \\
Si1Al3Si & -105 & 13.7 & 13.6 & 16.9 & 17.3 & 16.8 & 15.9 & 18.4 & 19.3 \\
Si4Si & -110 & 20.4 & 17.4 & 22.6 & 23.4 & 30.6 & 26.1 & 35.9 & 37.2 \\
\hline Si in silicon islands & -100 to -110 & 53 & 49.8 & 59.3 & 60.4 & 64.4 & 59.7 & 70.9 & 73.3 \\
\hline
\end{tabular}


Table 3. Kinetic parameters, halflifetime $\left(\mathrm{t}_{0.5}\right)$, breakthrough time $\left(\mathrm{t}_{0.8}\right)$, and methanol conversion capacity of nano and standard-SAPO-34 samples obtained by fitting of Janssen's kinetic model.

\begin{tabular}{ccccccc}
\hline Sample & $\begin{array}{c}\text { Days of } \\
\text { exposure } \\
\text { to } \\
\text { moisture }\end{array}$ & $\mathrm{k}(\mathrm{mol} / \mathrm{gh})$ & $\begin{array}{c}\mathrm{a} \\
(\mathrm{g} / \mathrm{mmol})\end{array}$ & $\begin{array}{c}\mathrm{t}_{0.5} \\
(\mathrm{~min})\end{array}$ & $\begin{array}{c}\mathrm{t}_{0.8} \\
(\mathrm{~min})\end{array}$ & $\begin{array}{c}\text { Methanol } \\
\text { conversion } \\
\text { capacity } \\
\text { (gmetanol/gcatalyst }\end{array}$ \\
\hline Nano SAPO-34 & 1 & 9.98 & 5.6 & 147 & 76.7 & 15.9 \\
& 28 & 6.82 & 3.6 & 231 & 70.0 & 25.1 \\
\hline Nano SAPO-34 & 7 & 5.51 & 5.5 & 149 & 20.4 & 16.2 \\
St. 700 ${ }^{\circ} \mathrm{C}$ & 53 & 5.47 & 6.3 & 131 & 17.2 & 14.2 \\
& 62 & 6.86 & 5.9 & 138 & 42.3 & 15.0 \\
\hline Nano SAPO-34 & 1 & 5.94 & 5.3 & 155 & 31.1 & 16.9 \\
St. 600 ${ }^{\circ} \mathrm{C}$ & 12 & 7.00 & 5.8 & 142 & 45.7 & 15.4 \\
& 22 & 8.85 & 6.8 & 120 & 55.5 & 13.0 \\
\hline Nano SAPO-34 & 1 & 9.08 & 5.5 & 149 & 71.2 & 16.2 \\
St. 550 ${ }^{\circ} \mathrm{C}$ & 7 & 7.70 & 4.9 & 167 & 63.8 & 18.1 \\
& 14 & 7.23 & 4.9 & 166 & 56.9 & 18.1 \\
\hline
\end{tabular}




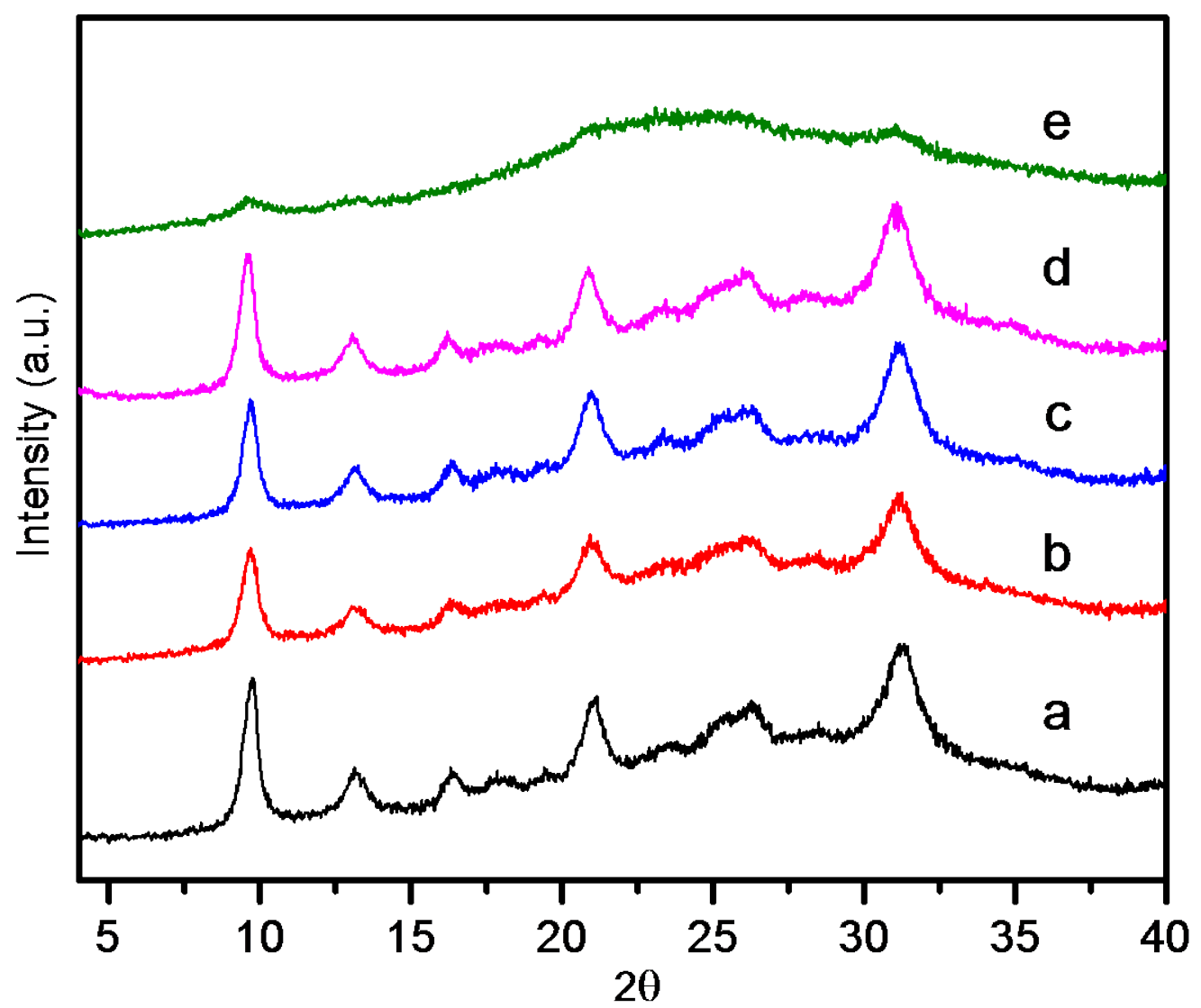

Figure 1. XRD patterns of nano-SAPO-34 (a) as calcined, and after steaming at (b) $700^{\circ} \mathrm{C},(\mathrm{c}) 600^{\circ} \mathrm{C},(\mathrm{d}) 550^{\circ} \mathrm{C},(\mathrm{e}) 400^{\circ} \mathrm{C}$. 

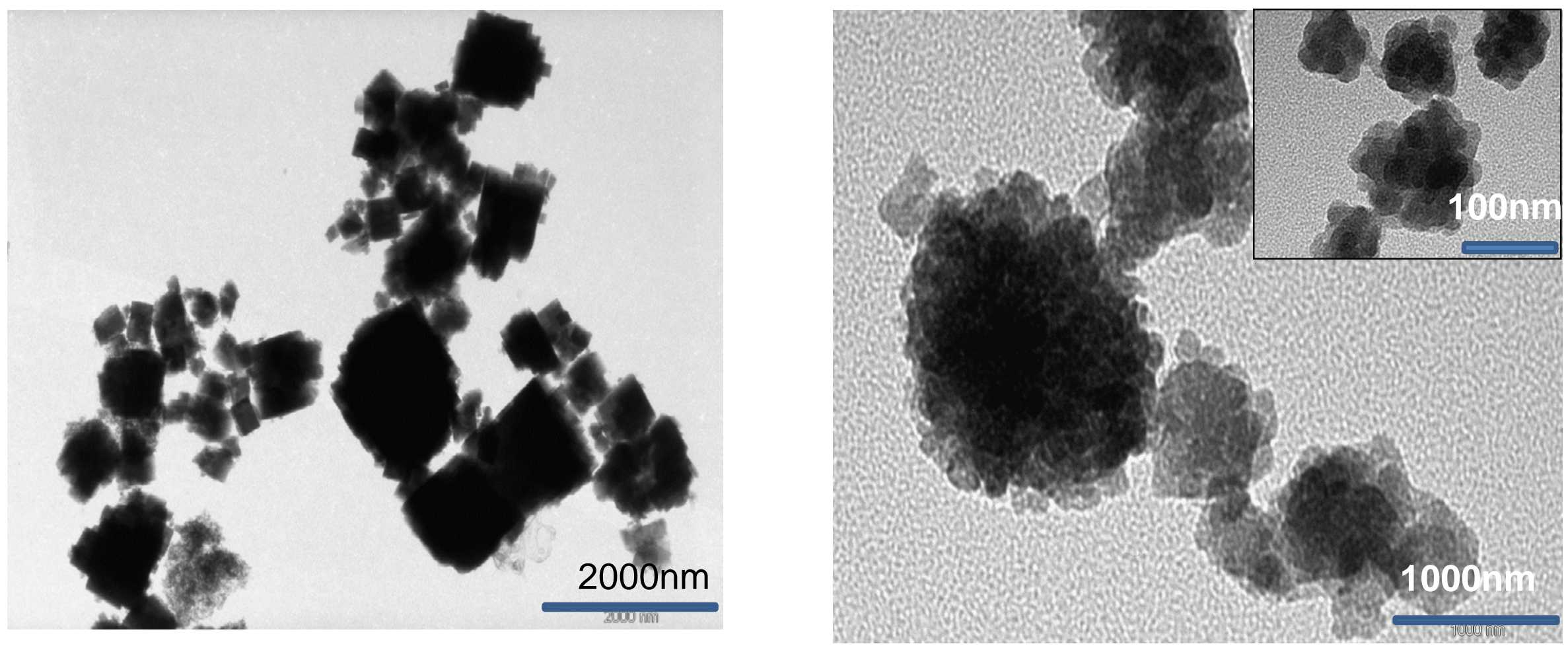

Figure 2. TEM pictures of standard and nano-SAPO-34. 


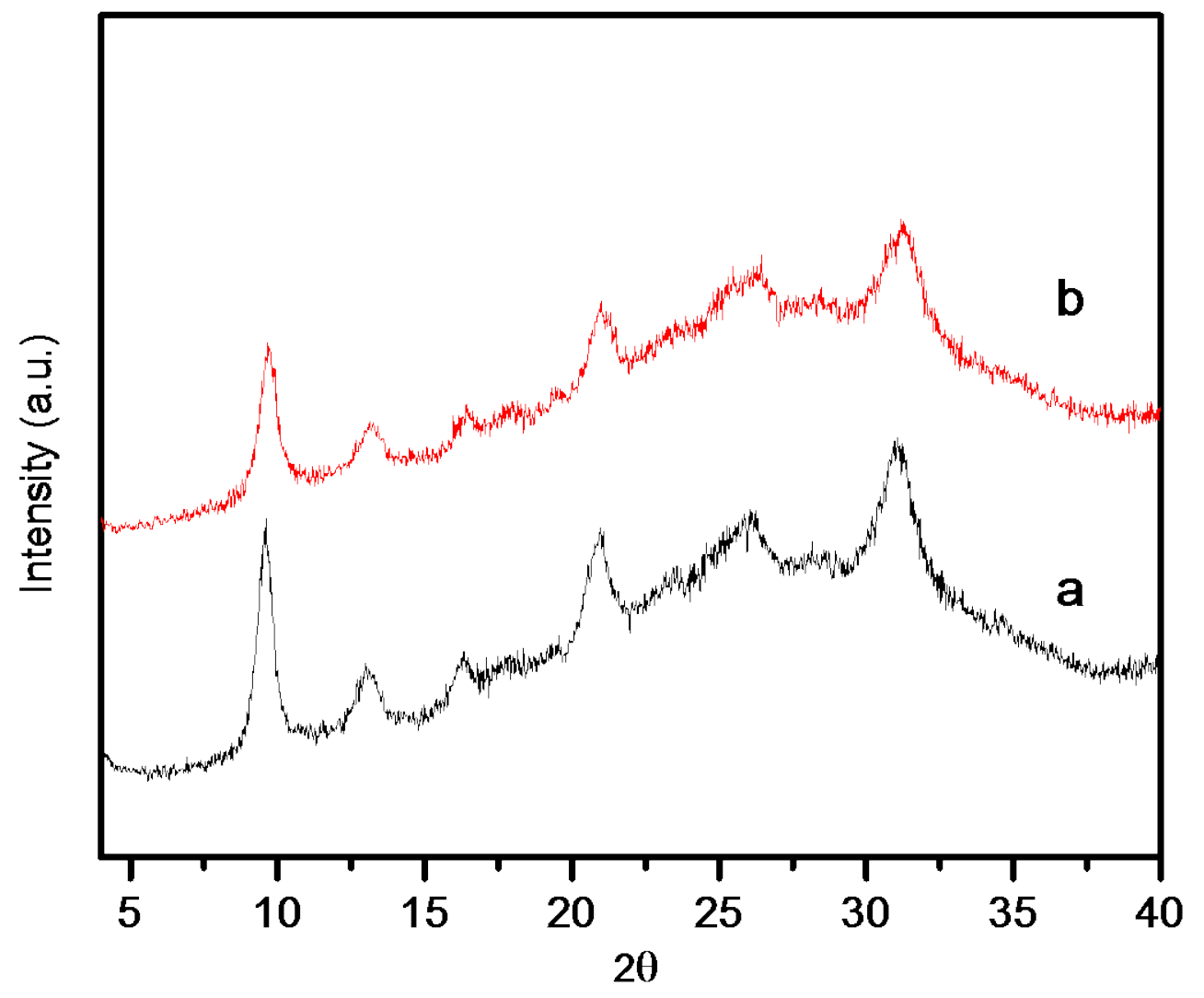

Figure 3. XRD patterns of nano-SAPO-34 steamed at $700^{\circ} \mathrm{C}$ after contact with moisture for (a) 1day ( b)67 days. 

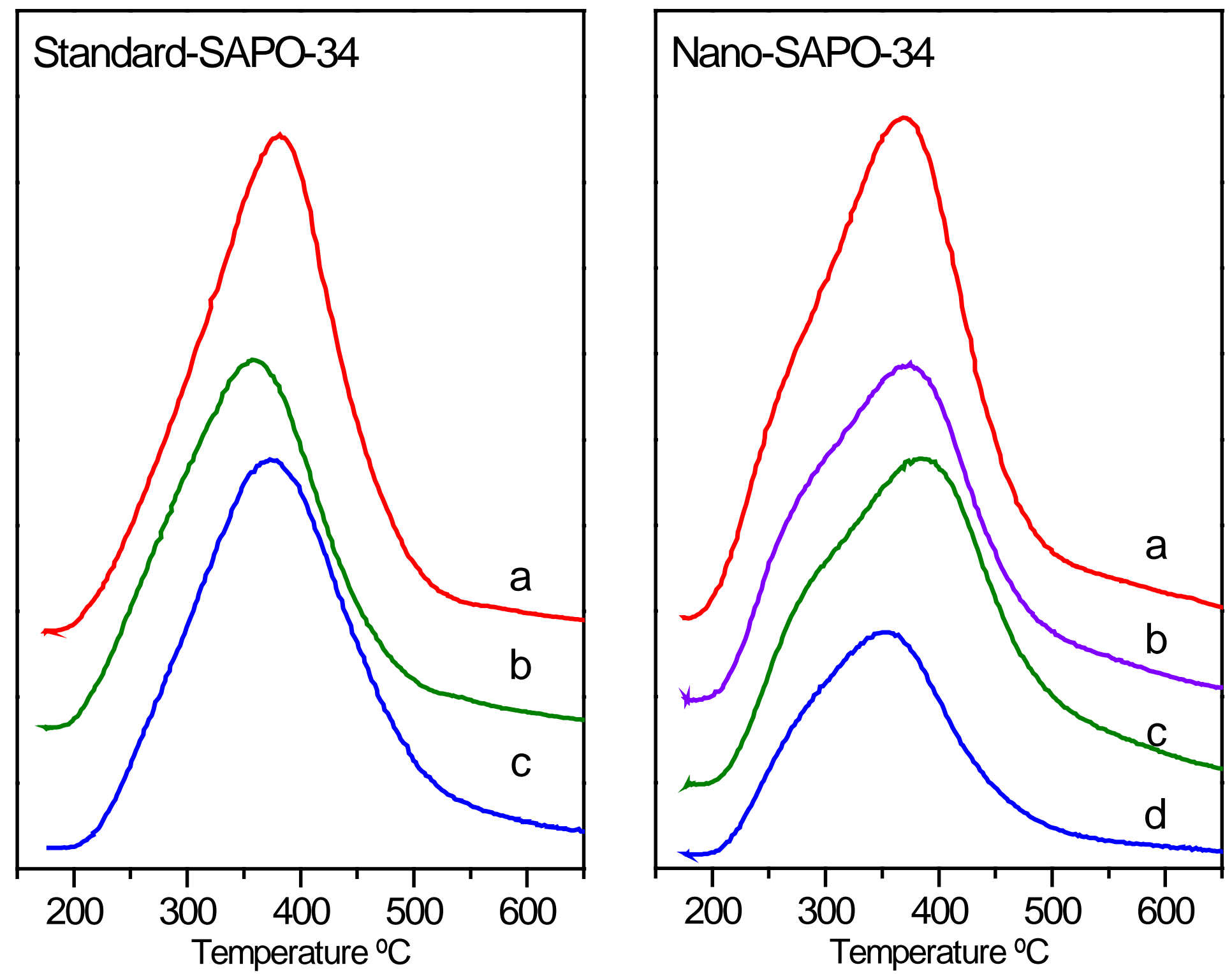

Figure 4. $\mathrm{NH}_{3}$-TPD of standard-SAPO-34 (a)fresh, (b)steamed at $400^{\circ} \mathrm{C}$, (c)steamed at $700^{\circ} \mathrm{C}$; and nano-SAPO-34 (a)fresh, and steamed at (b)550, (c)600 and (d) $700^{\circ} \mathrm{C}$. 


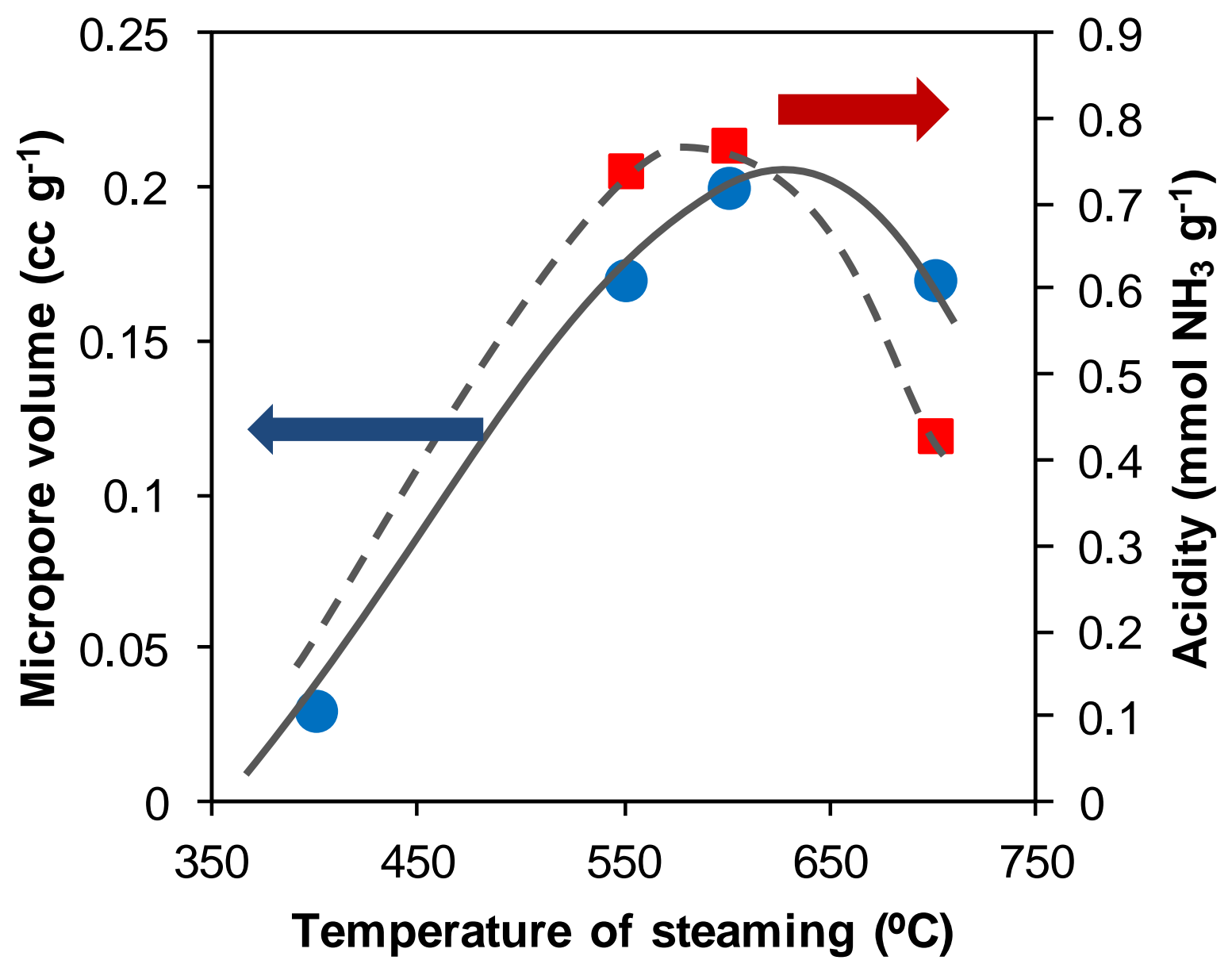

Figure 5. Micropore volume (circles) and acidity (squares) of nano-SAPO-34 samples steamed at different temperatures. 

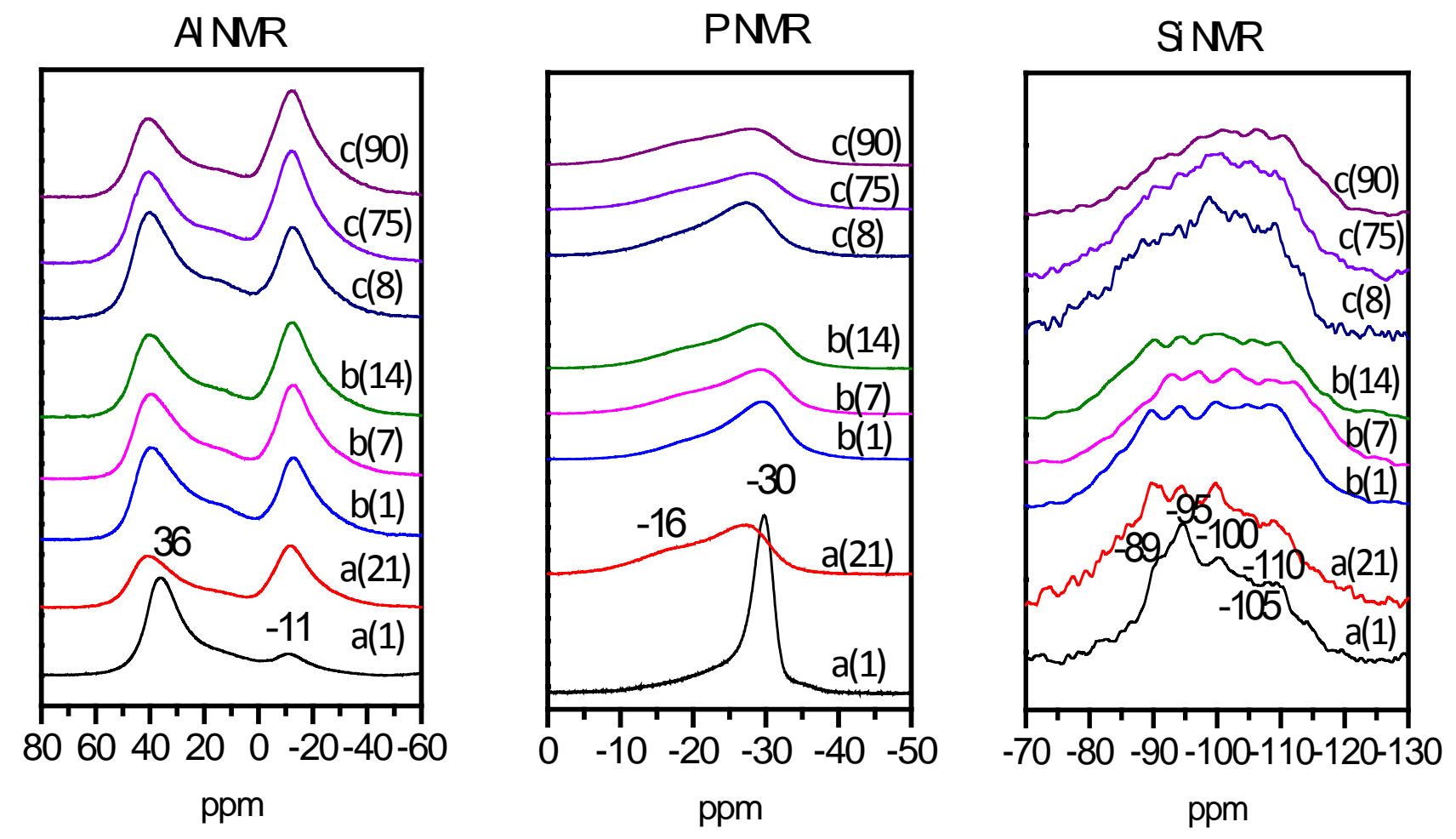

Figure 6. ${ }^{27} \mathrm{Al},{ }^{31} \mathrm{P}$ and ${ }^{29} \mathrm{Si}$ MAS NMR of nano-SAPO-34 samples (a)fresh and steamed at (b)600 or (c)700 ${ }^{\circ} \mathrm{C}$ followed by exposure to moisture at room temperature for ( ) days. 
Nano-SAPO-34 fresh and steamed at $700^{\circ} \mathrm{C}$

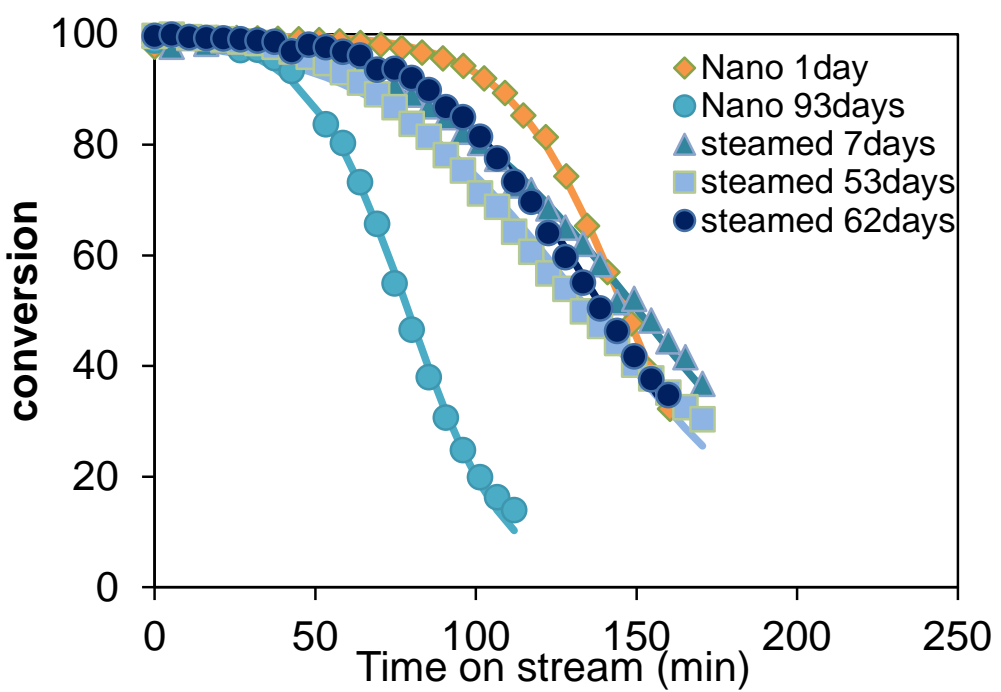

Nano-SAPO-34 steamed at $700^{\circ} \mathrm{C}$

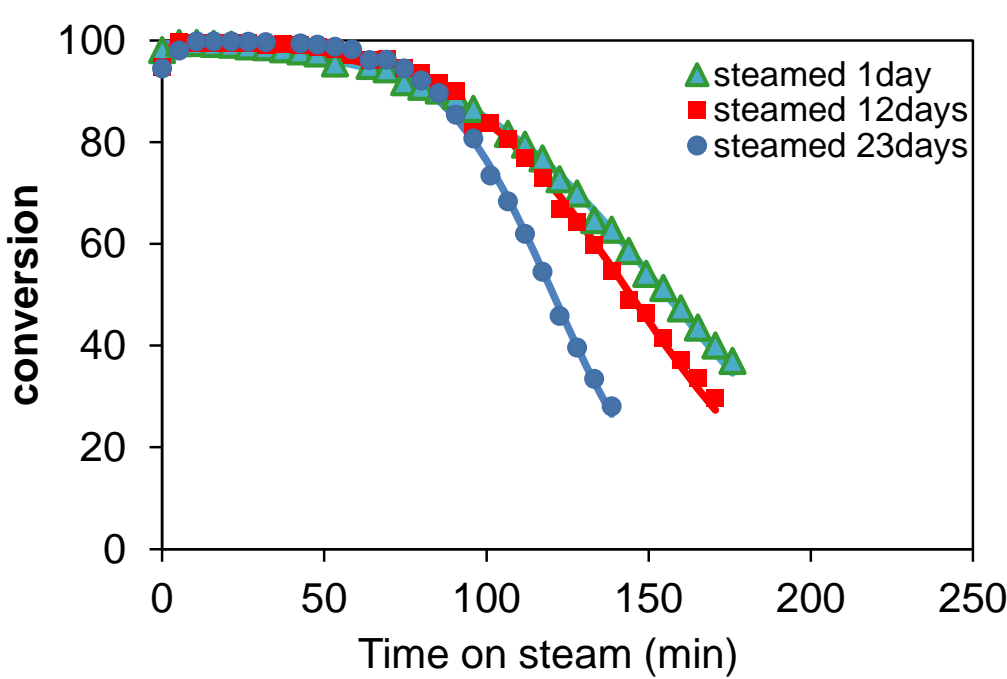

Standard-SAPO-34 fresh and steamed at $700^{\circ} \mathrm{C}$

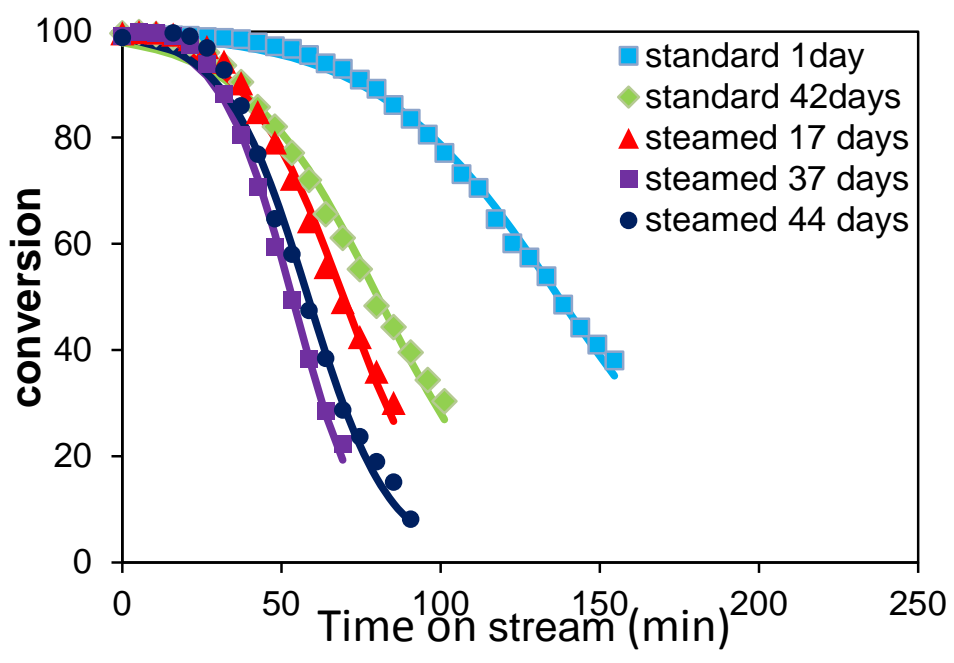

Nano-SAPO-34 steamed at $550^{\circ} \mathrm{C}$

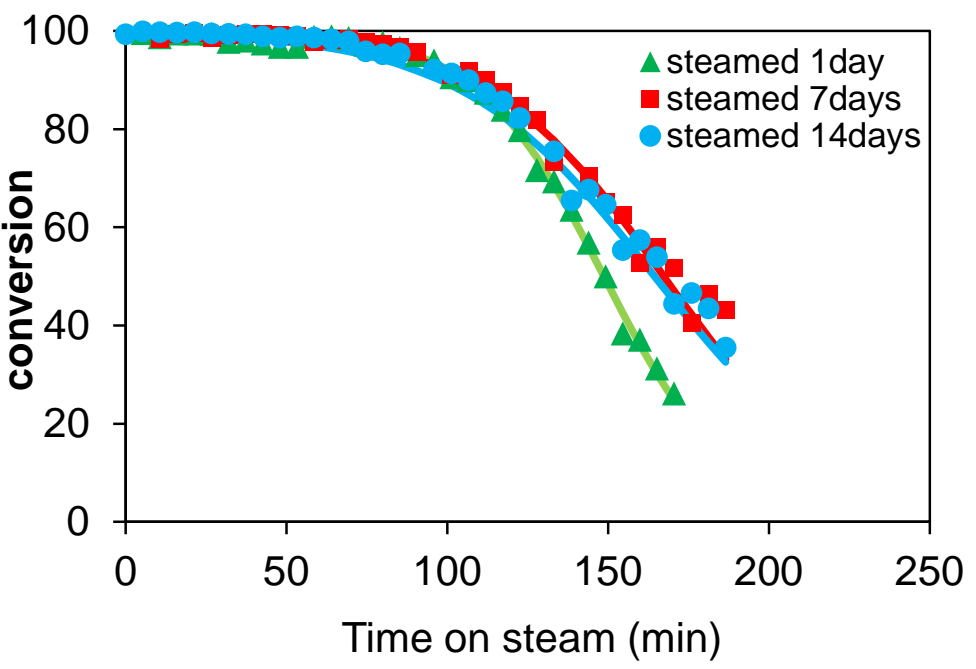

Figure 7. Conversion of methanol at $400^{\circ} \mathrm{C}$ and WHSV: $7 \mathrm{~h}^{-1}$ on nano-SAPO-34 and standard-SAPO-34 samples fresh, after steaming at different temperatures and subsequent exposure to moisture. Lines correspond to the fitting following Janssens's kinetic model. 


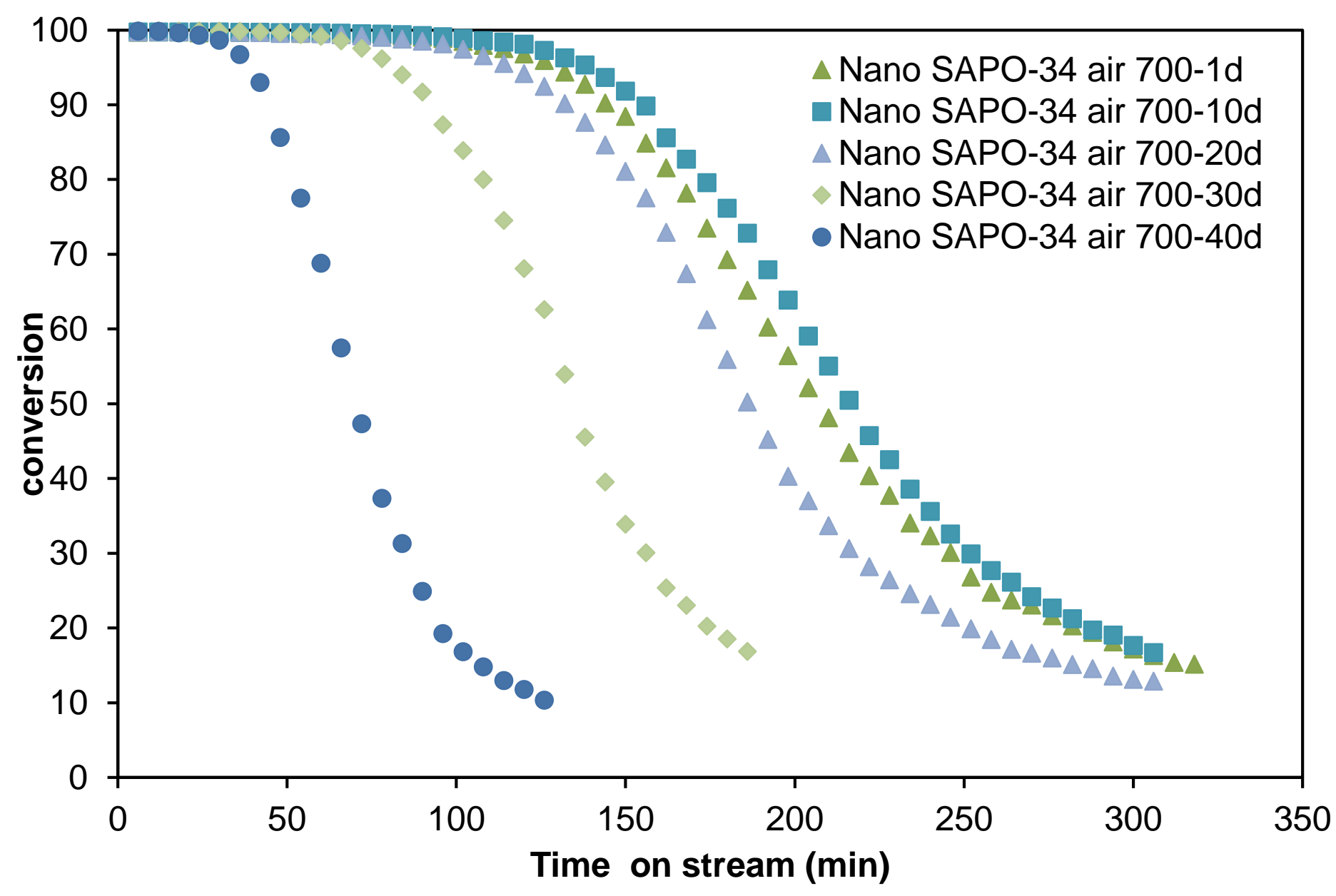

Figure 8. Conversion of methanol at $400^{\circ} \mathrm{C}$ and WHSV: $7 \mathrm{~h}^{-1}$ on nano-SAPO-34 thermally treated in air at $700^{\circ} \mathrm{C}$ for $5 \mathrm{~h}$ fresh and after contact with moisture at room temperature up to 40 days. 
a) Nano SAPO-34 1d

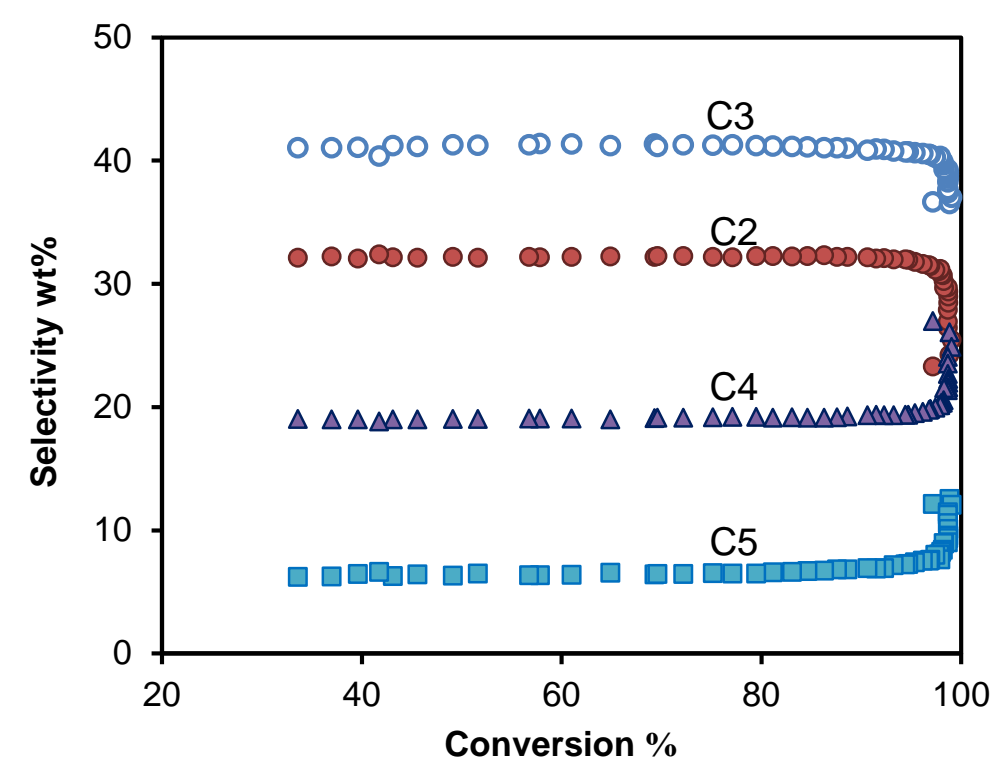

c) Nano SAPO-34 steamed at $600^{\circ} \mathrm{C}$

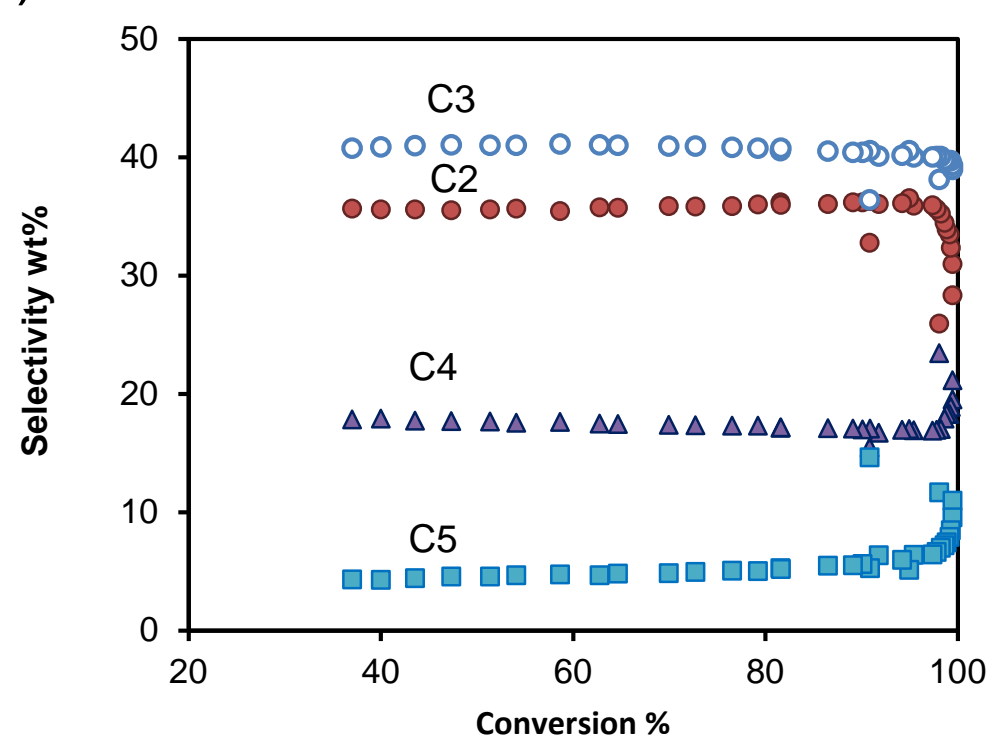

b) Nano SAPO-34 steamed at $700^{\circ} \mathrm{C}$

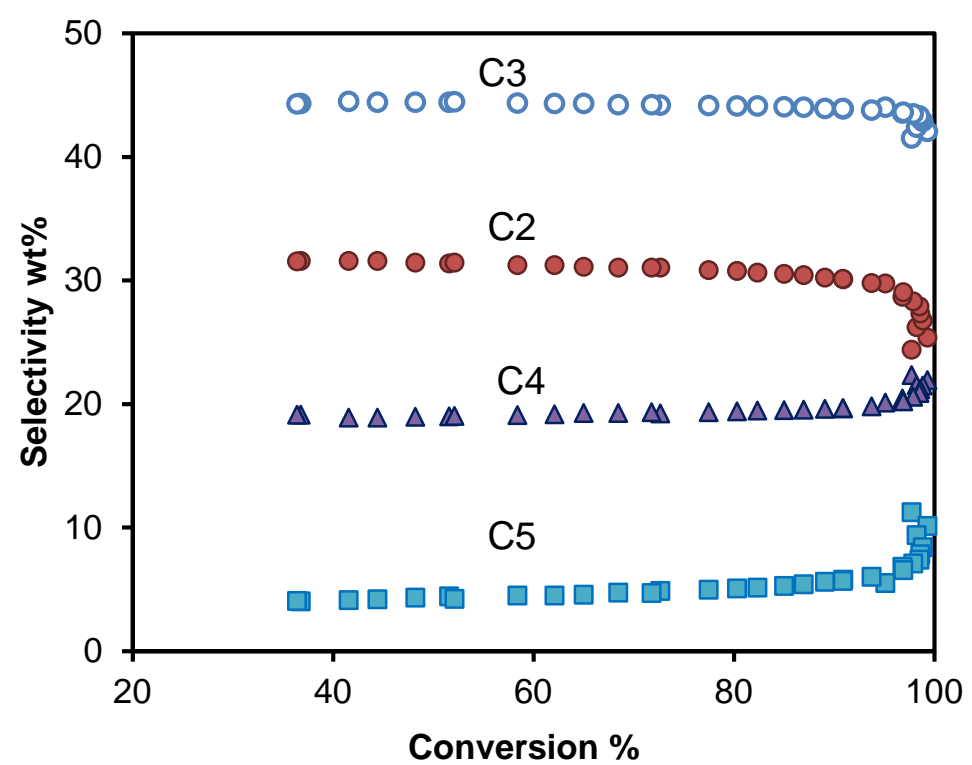

d) Nano SAPO-34 steamed at $550^{\circ} \mathrm{C}$

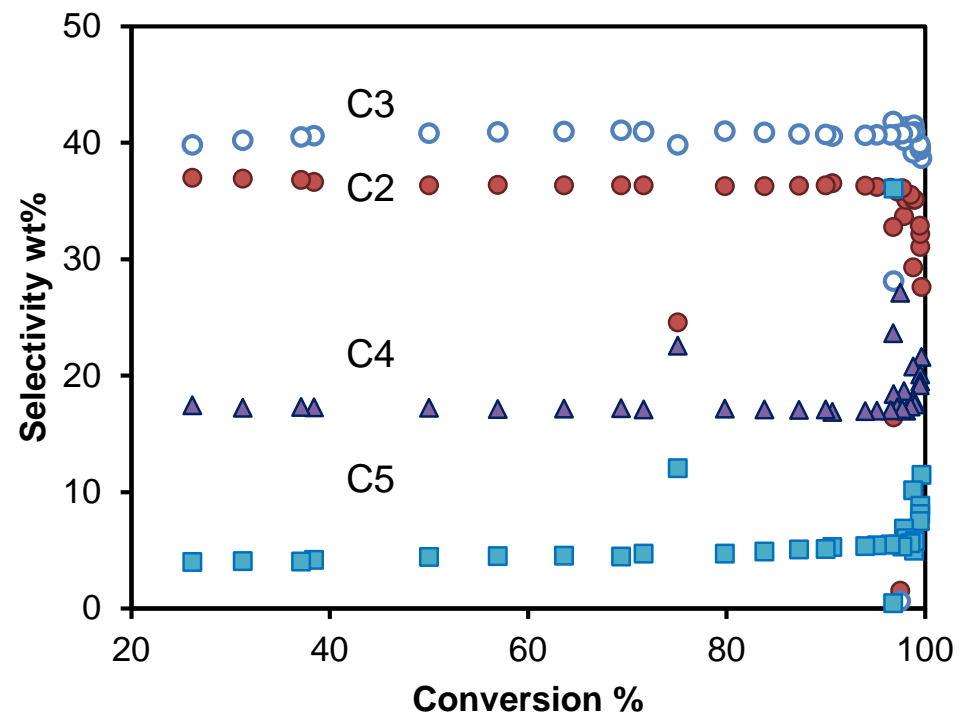

Figure 9. Selectivities to C2, C3, C4 and C5+ hydrocarbons in the conversion of methanol on nano-SAPO-34 fresh and steamed at 550, 600 and $700^{\circ} \mathrm{C}$. 


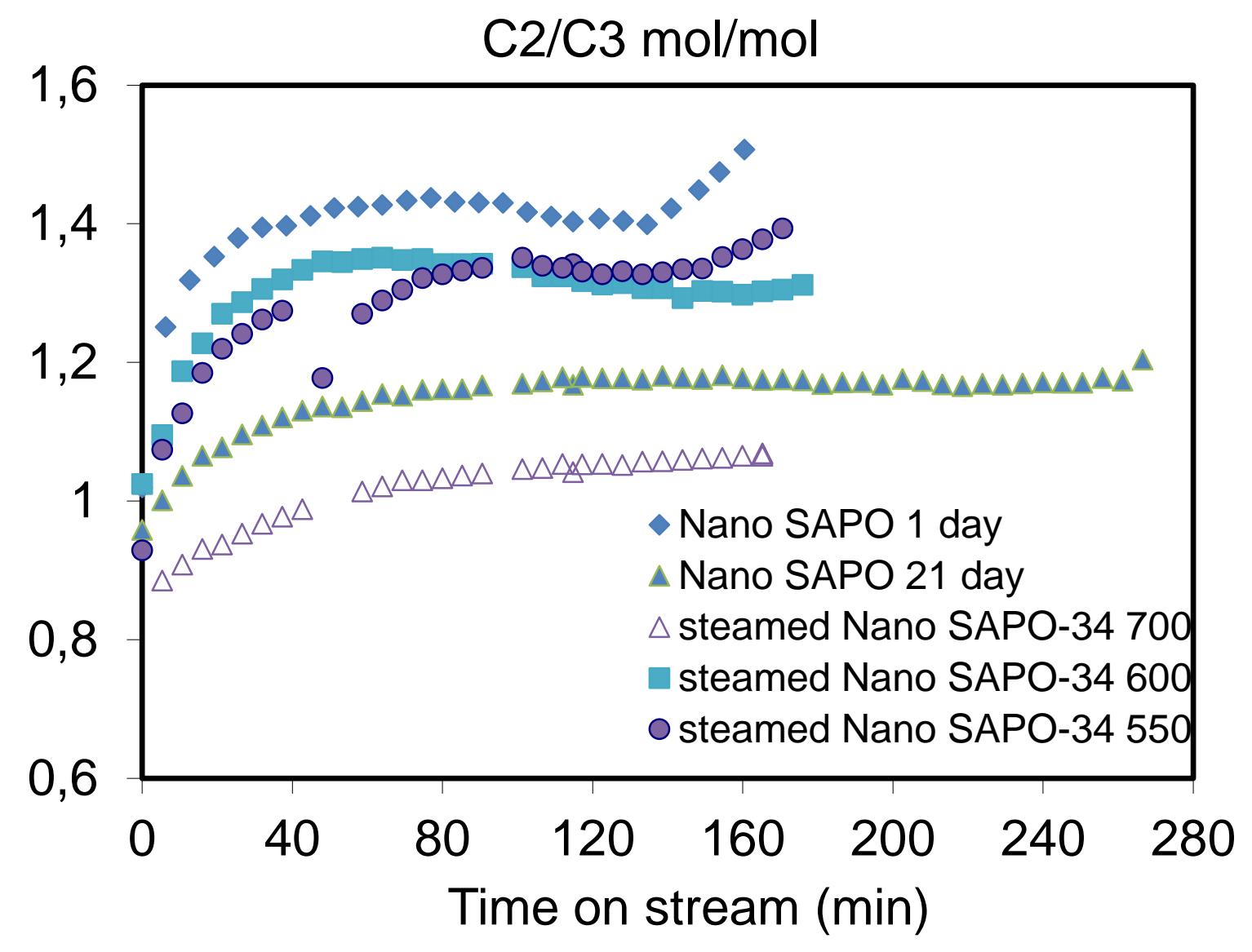

Fig. 10. C2/C3 ratio of products in the conversion of methanol at $400^{\circ} \mathrm{C}$ and WHSV $=7 \mathrm{~h}^{-1}$ on nano-SAPO-34 fresh and after steaming at 550, 600 and $700^{\circ} \mathrm{C}$. 